\title{
Recent Warming Has Resulted in Smaller Gains in Net Carbon Uptake in Northern High Latitudes ${ }^{\circ}$
}

\author{
Peng Zhu, ${ }^{\mathrm{a}}$ Qianlai Zhuang,,${ }^{\mathrm{a}, \mathrm{b}}$ Lisa Welp,${ }^{\mathrm{a}}$ Philippe Ciais, ${ }^{\mathrm{c}}$ Martin Heimann, ${ }^{\mathrm{d}}$ Bin Peng,, $\mathrm{f}$

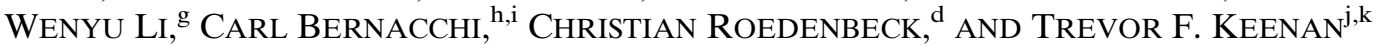 \\ ${ }^{a}$ Department of Earth, Atmospheric, and Planetary Sciences, Purdue University, West Lafayette, Indiana \\ ${ }^{\mathrm{b}}$ Department of Agronomy, Purdue University, West Lafayette, Indiana \\ ${ }^{\mathrm{c}}$ Laboratoire des Sciences du Climat et de l'Environnement (LSCE), CEA CNRS UVSQ, Gif-sur-Yvette, France \\ ${ }^{\mathrm{d}}$ Max Planck Institute for Biogeochemistry, Jena, Germany \\ ${ }^{\mathrm{e}}$ National Center for Supercomputing Applications, University of Illinois at Urbana-Champaign, Urbana, Illinois \\ ${ }^{\mathrm{f}}$ Department of Natural Resources and Environmental Sciences, University of Illinois at Urbana-Champaign, Urbana, Illinois \\ ${ }^{\mathrm{g}}$ Ministry of Education Key Laboratory for Earth System Modeling, Tsinghua University, Beijing, China \\ ${ }^{\mathrm{h}}$ Department of Plant Biology, University of Illinois at Urbana-Champaign, Urbana, Illinois \\ ${ }^{i}$ Global Change and Photosynthesis Research Unit, U.S. Department of Agriculture-Agricultural Research Service, Urbana, Illinois \\ ${ }^{\mathrm{j}}$ Earth Sciences Division, Lawrence Berkeley National Laboratory, Berkeley, California \\ ${ }^{\mathrm{k}}$ Department of Environmental Science, Policy and Management, University of California, Berkeley, Berkeley, California
}

(Manuscript received 4 October 2018, in final form 24 April 2019)

\begin{abstract}
Carbon balance of terrestrial ecosystems in the northern high latitudes (NHL) is sensitive to climate change. It remains uncertain whether current regional carbon uptake capacity can be sustained under future warming. Here the atmospheric $\mathrm{CO}_{2}$ drawdown rate (CDR) between 1974 and 2014, defined as the $\mathrm{CO}_{2}$ decrease in ppm over the number of days in spring or summer, is estimated using atmospheric $\mathrm{CO}_{2}$ observations at Barrow (now known as Utqiagvik), Alaska. We found that the sensitivity of CDR to interannual seasonal air temperature anomalies has trended toward less carbon uptake for a given amount of warming over this period. Changes in interannual temperature sensitivity of CDR suggest that relatively warm springs now result in less of a carbon uptake enhancement. Similarly, relatively warm summers now result in greater carbon release. These results generally agree with the sensitivity of net carbon exchange (NCE) estimated by atmospheric $\mathrm{CO}_{2}$ inversion. When NCE was aggregated over North America (NA) and Eurasia (EA), separately, the temperature sensitivity of NCE in NA has changed more than in EA. To explore potential mechanisms of this signal, we also examine trends in interannual variability of other climate variables (soil temperature and precipitation), satellite-derived gross primary production (GPP), and Trends in Net Land-Atmosphere Carbon Exchanges (TRENDY) model ensemble results. Our analysis suggests that the weakened spring sensitivity of CDR may be related to the slowdown in seasonal soil thawing rate, while the summer sensitivity change may be caused by the temporally coincident decrease in temperature sensitivity of photosynthesis. This study suggests that the current NHL carbon sink may become unsustainable as temperatures warm further. We also found that current carbon cycle models do not represent the decrease in temperature sensitivity of net carbon flux. We argue that current carbon-climate models misrepresent important aspect of the carbon-climate feedback and bias the estimation of warming influence on NHL carbon balance.
\end{abstract}

\section{Introduction}

The northern high latitudes (NHL; north of $50^{\circ} \mathrm{N}$ ) have experienced a greater surface warming than the global average in recent decades mainly attributed to

Supplemental information related to this paper is available at the Journals Online website: https://doi.org/10.1175/JCLI-D-180653.s1.

Corresponding author: Qianlai Zhuang, qzhuang@purdue.edu snow albedo feedbacks (McGuire et al. 2009). Warming has promoted plant growth in these temperature-limited regions through extending the growing season length (Nemani et al. 2003) and releasing more nitrogen from thawing permafrost soils (Keuper et al. 2012). Forward modeling studies and observation-based atmospheric inversions suggest that the net carbon uptake has increased (Hayes et al. 2011; Welp et al. 2016). However, correlations between spring temperature and changes in atmospheric $\mathrm{CO}_{2}$ concentrations suggest the positive effect of warming on net carbon uptake has weakened in 
recent years (Piao et al. 2017). Satellite observations of vegetation "greenness" suggest that there is a shift from widespread greening to browning trends since 2000 across the boreal zone possibly due to fire disturbance and drought stress (Goetz et al. 2005; Verbyla 2008, 2011). These findings were also supported by ground measurements, indicating that there is widespread tree mortality caused by insect outbreaks (Kurz et al. 2008) and water stress (Peng et al. 2011). On the other hand, rising atmospheric $\mathrm{CO}_{2}$ concentration leads to higher plant photosynthetic rates through $\mathrm{CO}_{2}$ fertilization and enhanced water use efficiency (Lloyd and Farquhar 1996). Forest growth sensitivity to climate variability has been analyzed using tree ring annual growth widths data, suggesting a weakened temperature sensitivity of tree growth in the boreal forest during the twentieth century, possibly due to warming-induced drier conditions (Barber et al. 2000; Walker and Johnstone 2014). Multiple drivers of change are clearly competing in this region and their effects on net primary productivity are not understood well.

Belowground soil organic carbon dynamics could be another important factor that determines the sign and magnitude of carbon exchange across the NHL, given the large amount of soil carbon stored in these areas and its sensitivity to temperature. It has been suggested that warming might stimulate soil organic carbon decomposition or ecosystem respiration in tundra ecosystems and thus lead to a positive feedback on climate warming (Pastick et al. 2015; Schuur et al. 2015). Rising temperature exposes previously frozen organic matter to decomposition by deepening the active layer thickness, and stimulating soil respiration (Koven et al. 2011). In addition, permafrost thaw could also increase $\mathrm{CO}_{2}$ production from soil organic decomposition through regulating soil moisture as the deepening active layer allows water to drain deeper into the soil column and dry the surface soil (Lawrence et al. 2015).

Whether NHL terrestrial ecosystems will become a carbon source to the atmosphere or remain a sink as temperature goes up remains uncertain. Various approaches including field experiments, process-based models, and atmospheric inversions have been employed to quantify the current trends in the carbon balance of boreal forest and tundra ecosystems and investigate the underlying mechanisms and sensitivity determining carbon uptake and emissions (McGuire et al. 2009; Hayes et al. 2011; Koven et al. 2011; Lawrence et al. 2015; Welp et al. 2016; Piao et al. 2017; Jeong et al. 2018).

Field measurements from eddy-covariance flux towers provide plot-scale evidence on how net carbon flux responds to climatic and hydrological variability on hourly to annual time scales. For example, carbon flux measurements across Alaska suggest that seasonal patterns of the $\mathrm{CO}_{2}$ fluxes were mostly determined by air temperature. However, the spatial variation of tundra ecosystems photosynthesis and net $\mathrm{CO}_{2}$ sink strength were mainly explained by growing season length (Ueyama et al. 2014). Synthesizing both growing season and winter $\mathrm{CO}_{2}$ flux measurements across tundra ecosystems suggests that, although net carbon uptake in growing season increased, carbon emissions in winter also increased. Taken together, tundra ecosystems changed from a carbon sink to a carbon source in the 2000s, since $\mathrm{CO}_{2}$ emissions exceed $\mathrm{CO}_{2}$ uptake across temperature gradients that occur in the tundra ecosystem (Belshe et al. 2013). This conclusion was also supported by a recent study based on the compilation of aircraft optimized $\mathrm{CO}_{2}$ flux and satellite observed solarinduced chlorophyll fluorescence datasets (Commane et al. 2017).

Within the boreal forest, the response of carbon fluxes to warming may vary by plant functional type (Welp et al. 2007). Eddy covariance $\mathrm{CO}_{2}$ flux analysis showed that interannual variability in net carbon fluxes in both spring and summer was greatest in the deciduous forest. Thus deciduous forests might be the largest contributor to the atmospheric $\mathrm{CO}_{2}$ concentration variability across the NHL (Welp et al. 2007). Therefore, potential shifts in forest plant functional types and biome shifts like shrub expansion into the tundra might also alter the response of ecosystem carbon uptake to warming (Cai et al. 2010; Forbes et al. 2010; Macias-Fauria et al. 2012).

Recently, there is evidence of a weakened relationship between $\mathrm{CO}_{2}$ drawdown and spring temperature in northern ecosystems (Piao et al. 2017). Model analysis also suggests that the NHL carbon sink might weaken due to warming enhanced soil organic carbon decomposition and increasing fire $\mathrm{CO}_{2}$ emissions (Hayes et al. 2011). Seasonally, under warming conditions, there are compensating and interactive effects of spring and summer carbon fluxes on carbon balance (Sippel et al. 2017). Factorial model experiments indicate that warmer springs result in high net carbon uptake, while warming in summer results in less net carbon uptake. Spring warming may reduce soil moisture later in the season and exacerbate carbon loss in summer (Angert et al. 2005; Sippel et al. 2017). However, the higher carbon uptake in spring could partly compensate for drought- or heat-induced carbon losses during summer. Taken together, these recent results challenge the longheld view that warmer temperature increases $\mathrm{CO}_{2}$ uptake in NHL.

This study extends the analysis by Piao et al. (2017) from the spring to the summer season and uses 
additional supporting evidence to investigate potential mechanisms behind the observed changes in temperature sensitivity from 1974 to 2014 . To this end, daily surface in situ records of atmospheric $\mathrm{CO}_{2}$ concentrations in Barrow (now known as Utqiagvik), Alaska (AK), from 1974 to 2014 was used to estimate the atmospheric $\mathrm{CO}_{2}$ drawdown rate (CDR) over spring and summer. The CDR is used as a proxy for the strength of NHL seasonal net $\mathrm{CO}_{2}$ uptake, given that the atmospheric $\mathrm{CO}_{2}$ seasonal cycle at Barrow is mainly driven by the seasonal changes in the imbalance between terrestrial carbon uptake and release in northern middle and high latitudes (Graven et al. 2013; Piao et al. 2017). We examined how the temperature sensitivity of detrended seasonal atmospheric $\mathrm{CO}_{2}$ drawdown has changed using a 17-yr moving time window from 1974 to 2014. By detrending, our analysis is focused on the interannual variability of the temperature sensitivity. We then used multiple diagnostic models of global photosynthesis and surface fluxes inferred from atmospheric inversions to verify our findings and investigated the possible driving factors. We found that our findings support the spring results of Piao et al. (2017), but show new trends in the summer season. We also provided an alternative mechanism to explain the weakening carbon uptake due to warmer climate.

\section{Datasets and methods}

\section{a. Atmospheric $\mathrm{CO}_{2}$ concentration data analysis}

Daily atmospheric $\mathrm{CO}_{2}$ concentration data from Barrow Observatory (Alaska) were obtained from the U.S. National Oceanic and Atmospheric Administration (NOAA) Earth System Research Laboratory (ESRL) for the period 1974-2014. To get the seasonal $\mathrm{CO}_{2}$ drawdown rate, we detrended the time series using the standard package CCGCRV from NOAA/ESRL (http:// www.esrl.noaa.gov/gmd/ccgg/mbl/crvfit/crvfit.html). The curve fit uses a second-order polynomial curve to remove most of the long-term trend in the atmospheric $\mathrm{CO}_{2}$ concentrations. The remaining $\mathrm{CO}_{2}$ variability was fit by four harmonic seasonal functions with high-frequency residuals filtered. The resulting harmonics plus the filtered residuals were used to construct the detrended $\mathrm{CO}_{2}$ seasonal cycle (DCSC).

Here we defined a metric, $\mathrm{CO}_{2}$ drawdown rate (CDR; ppm per days), to characterize the strength of the seasonal net carbon uptake across NHL. The CDR in spring and summer are calculated using the DCSC and the day of year (DOY) marking the start and end of the seasons (Fig. 1). The $\mathrm{CDR}$ in spring, $\mathrm{CDR}_{\text {spring, }}$, is defined as

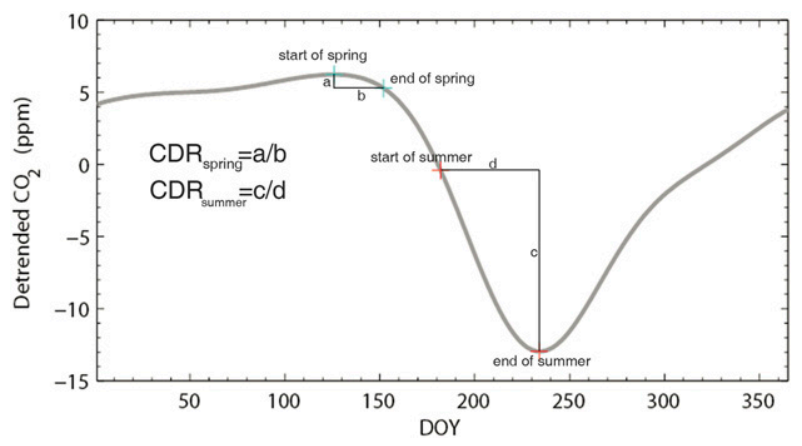

FIG. 1. Example of extracting carbon drawdown rate in spring and summer from detrended daily $\mathrm{CO}_{2}$ concentration record. The green cross in the curve corresponds to the starting and ending of spring $\mathrm{CO}_{2}$ concentration and the red cross corresponds to those of the summer $\mathrm{CO}_{2}$ concentration. As the figure shows, $\mathrm{CDR}_{\text {spring }}$ is determined by the ratio of $a$ to $b$ and $\mathrm{CDR}_{\text {summer }}$ is determined by the ratio of $c$ to $d$. Here absolute values of $a, b, c$, and $d$ were used to derive CDR and positive CDR suggests a net carbon uptake. The start of spring is determined by the date of the peak $\mathrm{CO}_{2}$ concentration during the spring (April-May). For the end of spring, we used two dates to test the robustness of our analysis. One is set as the last day of May, DOY 151, and the other is set as the last day of June, DOY 181. We also used two dates to define the start of summer. One is determined by the date when positive detrended $\mathrm{CO}_{2}$ concentrations become zero (sometimes referred to as the downward zero-crossing day) and the other is set as the start of July, DOY 182. The end of summer is defined as the last day of August, DOY 243.

$$
\mathrm{CDR}_{\text {spring }}=\frac{\mathrm{DCSC}_{\mathrm{SOS}}-\mathrm{DCSC}_{\mathrm{EOS}}}{\mathrm{DOY}_{\mathrm{EOS}}-\mathrm{DOY}_{\mathrm{SOS}}}
$$

and the $\mathrm{CDR}$ in summer $\left(\mathrm{CDR}_{\text {summer }}\right)$ is defined as

$$
\mathrm{CDR}_{\text {summer }}=\frac{\mathrm{DCSC}_{\mathrm{SOSM}}-\mathrm{DCSC}_{\mathrm{EOSM}}}{\mathrm{DOY}_{\mathrm{EOSM}}-\mathrm{DOY}_{\mathrm{SOSM}}} .
$$

The start of spring $\left(\mathrm{DOY}_{\mathrm{SOS}}\right)$ is determined by the date of the peak $\mathrm{CO}_{2}$ concentration during the spring (April-

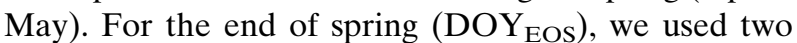
dates to test the robustness of our analysis. One is set as the last day of May (DOY 151), and the other is set as the last day of June (DOY 181). We also used two dates to define the start of summer $\left(\mathrm{DOY}_{\mathrm{SOSM}}\right)$. One is determined by the date when positive detrended $\mathrm{CO}_{2}$ concentrations become zero (sometimes referred to as the downward zero crossing day) and the other is set as the start of July (DOY 182). The end of summer $\left(\right.$ DOY $\left._{\text {EOSM }}\right)$ is defined as the last day of August (DOY 243).

As an alternative to the daily record, we also used the monthly $\mathrm{CO}_{2}$ record at Barrow. Monthly CDR is generated based on original $\mathrm{CO}_{2}$ record without using any curve-fitting and noise filtering. This monthly CDR 
(ppm per month) is created over the growing season from May to August and avoids the determination of season starting and ending date as in the daily $\mathrm{CO}_{2}$ record. For each year, the monthly CDR is calculated as: the mean $\mathrm{CO}_{2}$ concentration in May minus the mean $\mathrm{CO}_{2}$ concentration in August and then divided by 4 , which is the number of months during the season.

\section{b. Carbon flux products}

To help identify the processes by which the temperature sensitivity of the CDR changes over time, we examined the estimates of gross primary production (GPP) and net carbon exchange (NCE) over time and space. Data sources include monthly estimates of datadriven GPP from Jung et al. (2011), monthly light use efficiency model-derived GPP from Keenan et al. (2016), monthly land NCE from the Jena CarboScope atmospheric $\mathrm{CO}_{2}$ inversion, and NCE from nine terrestrial ecosystem models participating in the Trends in Net Land-Atmosphere Carbon Exchanges (TRENDY) model intercomparison project (Sitch et al. 2015).

Using the machine learning technique of model tree ensembles (MTE), the data-driven GPP (GPP $\left.\mathrm{MTE}_{\mathrm{MT}}\right)$ from Jung et al. (2011) covering 1982-2011 upscaled eddy covariance flux tower GPP data to global scale based on the satellite-observed fraction of absorbed photosynthetically active radiation (fPAR) and climate data. Note that $\mathrm{GPP}_{\mathrm{MTE}}$ depends on the flux tower data to train the model. Because there are very few flux sites in Eurasia during 1982-2011, large uncertainty may exist

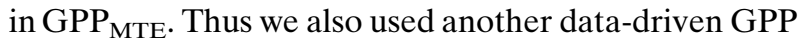
from Keenan et al. (2016), which covers 1982-2012 and is also based on satellite observed fPAR data but used a new light use efficiency model $\left(\mathrm{GPP}_{\mathrm{LUE}}\right)$ assuming the photosynthesis is colimited under average conditions by both electron transport capacity and RuBP (RuBP (ribulose-1,5-bisphosphate) regeneration. This LUE model ignores explicit nutrient limitations on LUE and disturbance impacts on GPP but accounts for them implicitly by using observed fPAR. More details can be found in Keenan et al. (2016).

Two versions of NCE from Jena CarboScope are used: s81_v3.7 and s99_v3.7 (Rödenbeck 2005). The s81 NCE estimates are based on 14 global atmospheric $\mathrm{CO}_{2}$ observation sites covering the period from 1981 to 2014. The s99 NCE estimates are based on 57 global sites covering the period from 1999 to 2014. Another NCE dataset (CarbonTracker, 2016 version) was also used as an independent data source to strengthen our analysis. CarbonTracker data were provided by Wageningen University (www.carbontracker.eu) (Peters et al. 2010). Its posterior biospheric fluxes are derived by optimization of modeled prior net carbon exchange data using the Simple Biosphere/Carnegie-Ames-Stanford Approach (SiBCASA) and atmospheric in situ $\mathrm{CO}_{2}$ observations as well as the atmospheric transport model TM5.

The nine models from the TRENDY project, which compiles outputs from a group of dynamic global vegetation models (DGVMs) to evaluate trends and drivers in land-atmosphere carbon exchange, were analyzed. The models providing NCE estimates are HYLAND, Lund-Potsdam-Jena DGVM (LPJ), ORCHIDEE, TRIFFID, Sheffield-DGVM, LPJGUESS, CLM4CN, OCN, and VEGAS. More details for each ecosystem model can be found in Table S2 in the online supplemental material. The NCE estimates cover the historic period of 1901-2010 and are derived from simulations in which all the models are forced by the same values of changing atmospheric $\mathrm{CO}_{2}$ concentrations, historical climate, and human-induced land-cover changes.

Here positive NCE indicates a net carbon uptake while negative NCE indicates a net carbon release. NCE from TRENDY is estimated by bottom-up ecosystem models through explicitly parameterizing related ecosystem processes. In contrast, NCE from Jena s81 and s99 is estimated by top-down inversion model using atmospheric $\mathrm{CO}_{2}$ measurement as constraint and thus implicitly accounts for the actual disturbances.

The spatial grids of the TRENDY model NCE output and inverse model NCE results vary in size, so for spatial consistency, all of the gridded datasets were regridded to $1^{\circ}$ latitude $\times 1^{\circ}$ longitude spatial resolution with nearest neighbor interpolation except the NCE datasets. Jena NCE datasets have a spatial resolution of $2.5^{\circ}$ latitude $\times$ $2.5^{\circ}$ longitude and each value represents the total carbon flux of the grid cell, not measured per area like the other datasets. So the total carbon fluxes in each $2.5^{\circ} \times 2.5^{\circ}$ were allocated to $1^{\circ} \times 1^{\circ}$ grid cell directly proportional to its percentage of vegetation cover in the $2.5^{\circ} \times 2.5^{\circ}$ grid cell.

\section{c. Climate datasets}

We used the daily and monthly mean surface air temperature (Tsa) and precipitation (Prec) data from 1974 to 2014 developed by the Terrestrial Hydrology Research Group at Princeton University, Princeton, New Jersey (Sheffield et al. 2006; http://hydrology. princeton.edu/data.pgf.php). This dataset has a spatial resolution of $0.5^{\circ} \times 0.5^{\circ}$ covering 1940-2014 and was constructed by synthesizing several global observationbased temperature and precipitation datasets, including the joint reanalysis product from the National Centers for Environmental Prediction-National Center for Atmospheric Research (NCEP-NCAR) (Kalnay et al. 1996), the Climatic Research Unit (CRU) monthly product (Mitchell and Jones 2005), the Global Precipitation 
Climatology Project (GPCP) daily product (Huffman et al. 2001), and the Tropical Rainfall Measuring Mission (TRMM) 3-h product (Huffman et al. 2007). This dataset has been widely used as climatic forcing data of ecosystem models across the northern high latitudes (Koven et al. 2011; Burke et al. 2013; Liu et al. 2015). However, it is inevitable that the bias in climate forcing data might introduce uncertainty to the analysis of temperature sensitivity of carbon flux (Ahlström et al.2017), especially given that the satellite-based precipitation product (TRMM) is missing in high latitudes.

When we use the end of May as DOY $\mathrm{EOS}_{\text {, climate }}$ variables during May are used to represent the spring climate. When we use the end of June as spring ending, climate variables during May and June are used to represent the spring climate. The two different definitions of the start of summer do not influence the summer period significantly, so we use climate variables during July and August to represent the summer climate for the two definitions.

We used the freezing degree-days (FDD) to characterize the soil thermal status (Frauenfeld et al. 2007). FDD is daily degrees below freezing (here we set it as $0^{\circ} \mathrm{C}$ ), which is calculated as the sum of average daily soil temperature below zero from January to June (Frauenfeld et al. 2007). Soil temperature was provided by ECMWF interim reanalysis (ERA-Interim) product, which is available at four depths $(0-7,7-28,28-100$, and $100-289 \mathrm{~cm})$ (Balsamo et al. 2009). Here we calculated FDD with the soil temperature averaged over the 1-m soil column. The model forecast for the land surface variables is provided by the Hydrology-Tiled ECMWF Scheme for Surface Exchanges over Land LSM (HTESSEL) (Balsamo et al. 2009). Evaluation of the time series soil temperature against in situ measurements shows a good performance in capturing both annual and diurnal cycles of soil temperature (Albergel et al. 2015).

We further used a teleconnection index representing the atmosphere-ocean variability patterns influencing the Northern Hemisphere climate anomalies: the Atlantic multidecadal oscillation (AMO) spanning 19742014. The AMO is the detrended North Atlantic sea surface temperature anomaly, averaged using area weighting over the $0^{\circ}-70^{\circ} \mathrm{N}$ belt (Steinman et al. 2015), obtained by NOAA's Physical Sciences Division (http:// www.ncdc.noaa.gov/teleconnections/). Here we used the January-May mean AMO value to characterize this decadal climate variability in spring.

\section{d. Statistical methods}

We used two different statistical methods (i.e., partial correlation and multiple linear regression) to diagnose the temperature response of CDR in each 17-yr moving

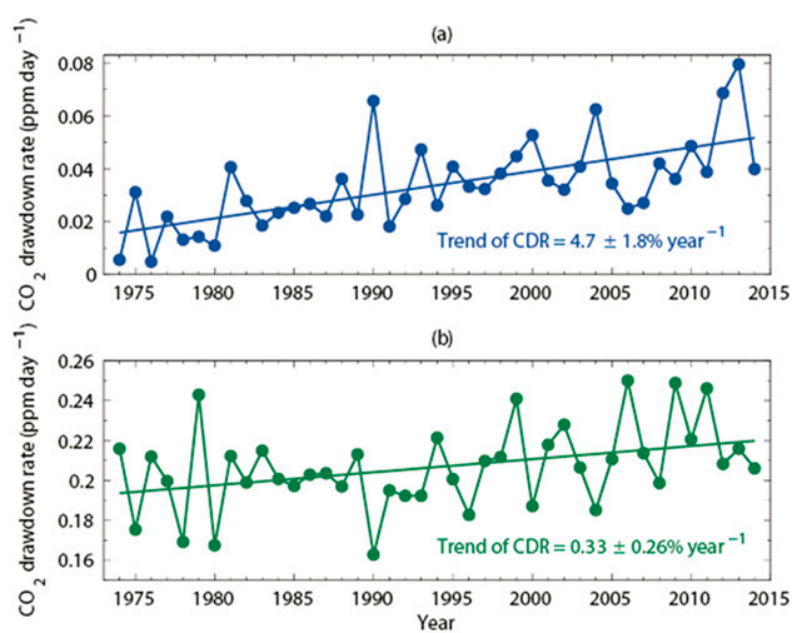

FIG. 2. Trend in (a) spring and (b) summer CDR (ppm day ${ }^{-1}$ ) over 1974-2014. Trend in CDR is divided by the first 10-yr mean CDR to get its percentage change per year. Here spring CDR is calculated using end of May as the end of spring and summer CDR is calculated using downward zero-crossing date as the start of summer.

window from 1974 to 2014. Area-weighted spring and summer Tsa and Prec are calculated for vegetated (annual mean NDVI $>0.1$ ) regions above $50^{\circ} \mathrm{N}$. As we focused on the interannual relationship between carbon flux and climatic drivers, the time series variables, Tsa, Prec, and CDR, are detrended by their first-order differences with respect to adjacent years to remove the autocorrelations in each 17 -yr window.

Partial correlation coefficients were used to represent the degree of colinearity between detrended CDR and Tsa. The partial correlation coefficient between the detrended CDR and Tsa was calculated with control on precipitation in each $17-\mathrm{yr}$ moving window for both spring and summer seasons. In statistics, partial correlation measures the association between two variables after removing the statistical influence of other confounding variables (like precipitation here).

We then used multiple linear regression of detrended CDR over both detrended Tsa and Prec to characterize the magnitude of the temperature sensitivity of CDR. The temperature sensitivity ( $d \mathrm{CDR} / d \mathrm{Tsa}$ ) was normalized by mean CDR over the period of 1974-2014 [i.e., $\left.d \mathrm{CDR} /(\mathrm{CDR} \times d \mathrm{Tsa})\left(\sigma_{\mathrm{CDR} / \mathrm{Tsa}} ; \% \mathrm{~K}^{-1}\right)\right]$. Thus positive values mean warmer temperature will boost a carbon sink, while negative $\sigma_{\mathrm{CDR} / \mathrm{Tsa}}$ means a carbon sink will be weakened in warmer conditions. Similar to CDR, temperature sensitivities of model based GPP $\left(\sigma_{\mathrm{GPP} / \mathrm{Tsa}}\right)$ and NCE $\left(\sigma_{\mathrm{NCE} / \mathrm{Tsa}}\right)$ were also estimated through multiple linear regression and expressed as $d \mathrm{GPP} /(\mathrm{GPP} \times$ $d \mathrm{Tsa})$ and $d \mathrm{NCE} /(\mathrm{NCE} \times d \mathrm{Tsa})$, respectively. By standardizing against climatological mean value of each 

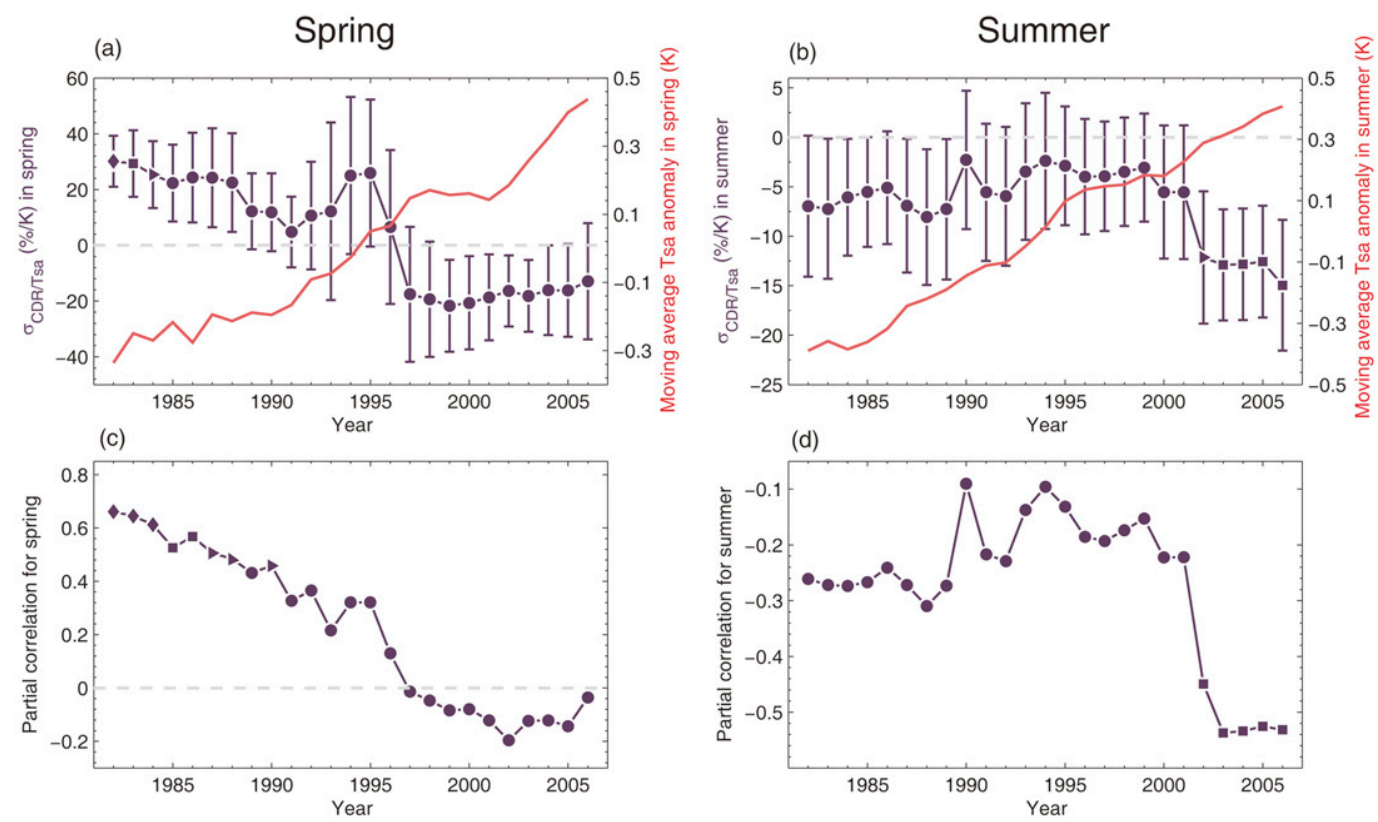

FIG. 3. Temporal evolution of the partial correlation between $\mathrm{CO}_{2}$ drawdown rate and Tsa as well as $\sigma_{\mathrm{CDR} / \mathrm{Tsa}}$ over 17-yr moving windows, and moving average of Tsa anomaly in spring and summer over northern high latitudes. (a),(b) The temperature sensitivity of $\mathrm{CDR}\left(\sigma_{\mathrm{CDR} / \mathrm{Tsa}} ; \% \mathrm{~K}^{-1}\right)$ and 17 -yr moving average Tsa anomaly for spring and summer. The value of $\sigma_{\mathrm{CDR} / \mathrm{Tsa}}$ is obtained by standardization using the mean CDR to get the percentage change per K. Positive $\sigma_{\mathrm{CDR} / \mathrm{Tsa}}$ means warmer temperatures will boost the carbon sink, while negative $\sigma_{\mathrm{CDR} / \mathrm{Tsa}}$ means the carbon sink will be weakened. (c),(d) The partial correlation between CDR and Tsa in spring and summer when controlling for Prec sensitivity. Here spring CDR is derived using the end of May (DOY 151) as the end of spring and summer CDR is derived using the downward zero crossing date as the start of summer. All of the variables are detrended by its first-order difference before doing correlation and regression. Years on the horizontal axis indicate the central year of the moving time window used to derive $\sigma_{\mathrm{CDR} / \mathrm{Tsa}}$ (e.g., 1998 represents the period 1990-2006 in the 17-yr time window). The symbols indicate the statistical significance of the partial correlation or multiple linear regression: diamond $=$ significant at $p<0.01$; square $=$ significant at $p<0.05$; triangle $=$ significant at $p<0.1$; round spot $p>0.1$. The error bars indicate the standard errors derived from $17-\mathrm{yr}$ moving windows with 5000 bootstrap estimates.

variable (CDR, GPP, and NCE), all the above-defined temperature sensitivities have the same unit $\left(\% \mathrm{~K}^{-1}\right)$.

\section{Results}

Spring CDR (not detrended) increased significantly during the study period by $4.7 \% \pm 1.8 \% \mathrm{yr}^{-1}(p<0.001)$ (Fig. 2). In comparison, the summer CDR also increased significantly $\left(0.33 \% \pm 0.26 \% \mathrm{yr}^{-1} ; p<0.05\right)$, but at a slower pace. The corresponding 17 -yr moving average temperature increased by approximately $0.8 \mathrm{~K}$ in spring and summer, respectively (Figs. 3a,b). The increased CDR is consistent with increased seasonal peak-totrough amplitudes and suggests an enhanced $\mathrm{CO}_{2}$ uptake strength between 1974 and 2014, especially in spring (Graven et al. 2013). The sensitivity of detrended CDR to temperature between 1974 and $2014\left(\sigma_{\mathrm{CDR} / \mathrm{Tsa}}\right)$ changed over time in both the spring and summer (Figs. 3a,b). Spring $\sigma_{\mathrm{CDR} / \mathrm{Tsa}}$ declined from a significant value of $30 \% \mathrm{~K}^{-1}$ at the beginning of the record
(1974-2014) to an insignificantly negative value of $-9 \%$ $\mathrm{K}^{-1}$ at the end of the record (Fig. 3a). However, the summer $\sigma_{\mathrm{CDR} / \mathrm{Ts}}$ decreased from an insignificant value of $-7 \% \mathrm{~K}^{-1}$ at the beginning of the record (1974-2014) to a significant $(p<0.05)$ value of $-15 \% \mathrm{~K}^{-1}$ at the end of the record (Fig. 3b). The partial correlation coefficients between CDR and Tsa show decreasing trends, with spring correlation becoming less significant and summer correlation becoming more significant (Figs. 3c,d).

An alternative definition of spring and summer season yields a similar downward trend in both spring and summer $\sigma_{\mathrm{CDR} / \mathrm{Tsa}}$ (shown in Fig. S1). Further, we found a consistent decrease in $\sigma_{\mathrm{CDR} / \mathrm{Tsa}}$ when not accounting for the influence of precipitation, when not using detrended data, and with different moving time windows of 15 and 19 years (Figs. S2 and S3). When a seasonal CDR for each year was derived based on monthly data for May-August, we obtained a similar decrease in temperature sensitivity of CDR (from positive to negative) over the study period for the whole 


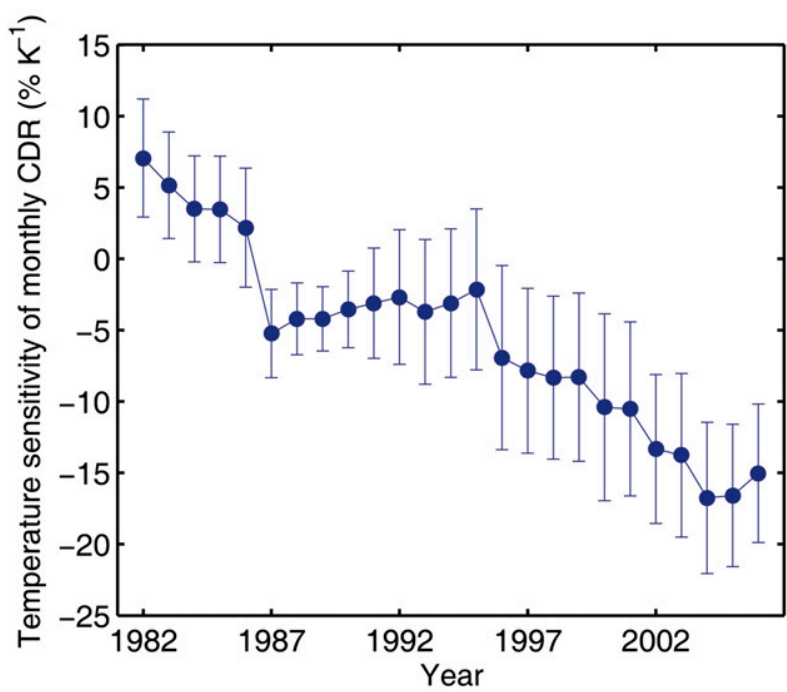

FIG. 4. Temperature sensitivity of monthly CDR in the $17-\mathrm{yr}$ time window from 1974 to 2014 over northern high latitude. The error bars means the standard errors with bootstrap estimates.

NHL (Fig. 4), suggesting that for the entire growing season in the NHL region the interannual temperature sensitivity of net carbon uptake has transitioned to less $\mathrm{CO}_{2}$ uptake during warmer years.

This analysis showed a weakened contribution of spring warming to enhanced NHL net carbon uptake and even a more negative contribution of summer warming to net carbon uptake over time. These trends may be driven by changes in the terrestrial biosphere response to temperature. However, northern highlatitude CDR is influenced by multiple confounding factors: atmospheric transport, ocean gas exchange, fires, and remote fluxes from natural and anthropogenic sources (Parazoo et al. 2016; Barnes et al. 2016; Sweeney et al. 2015), making it challenging to unambiguously identify terrestrial influences.

A high correlation between direct top-down estimation of net carbon flux data and CDR strengthened our conclusion. NCE from inversions is constrained by the atmospheric $\mathrm{CO}_{2}$ records from multiple stations while CDR from Barrow is also influenced by transport, nonland $\mathrm{CO}_{2}$ fluxes, and by specific land regions throughout the pan-Arctic and lower latitudes (Commane et al. 2017; Parazoo et al. 2016). Irrespective of these discrepancies, there is still a high correlation between monthly CDR and NCE $\left(r^{2}=0.72\right)$ over the growing season (Fig. 5).

Two different versions of the Jena $\mathrm{CO}_{2}$ inversion (Rödenbeck 2005) (Jena s81 and s99) were analyzed and $\sigma_{\mathrm{NCE} / \mathrm{Tsa}}$ shows a similar decreasing pattern as $\sigma_{\mathrm{CDR} / \mathrm{Tsa}}$. The s81 $\sigma_{\mathrm{NCE} / \mathrm{Tsa}}$ has a downward trend that is similar to that of $\sigma_{\mathrm{CDR} / \mathrm{Tsa}}$ for both spring and summer (Figs. 6a,b).

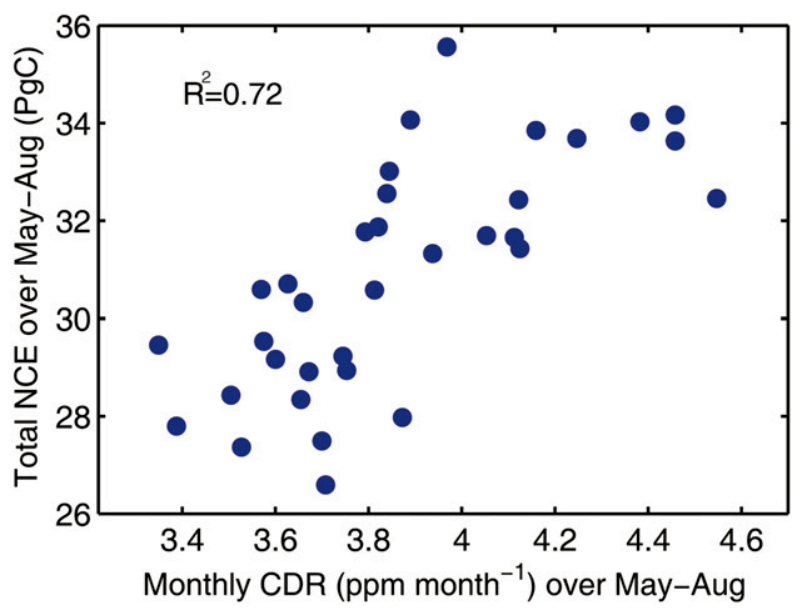

FIG. 5. The correlation between monthly CDR over MayAugust and total monthly net carbon exchange (NCE; s81 inversion) over May-August for 1981-2014 over north of $50^{\circ} \mathrm{N}$. Here NCE is inverted and positive value means carbon sinks.

These consistent findings are encouraging, since the inversion incorporates data from BRW as well as other Arctic stations. Both spring and summer $\sigma_{\mathrm{NCE} / \mathrm{Tsa}}$ from the inversion in North America (NA) shows a larger decrease compared to $\sigma_{\mathrm{NCE} / \mathrm{Tsa}}$ in Eurasia (EA) (Fig. S4), implying that terrestrial ecosystems in NA might be more dominant in determining the changing temperature sensitivity of CDR. This is also represented in the spatial pattern of $\sigma_{\mathrm{NCE} / \mathrm{Ts}}$, where more areas in NA show a decreasing temperature sensitivity of net carbon uptake (Fig. 7). Here both $\sigma_{\mathrm{CDR} / \mathrm{Tsa}}$ and $\sigma_{\mathrm{NCE} / \mathrm{Tsa}}$ are consistent and confirm the weakened positive impact of spring warming and intensified negative impact of summer warming on interannual net carbon uptake. Note here that this negative interannual sensitivity does not necessarily mean a long-term negative trend in net carbon uptake.

Another inversion carbon flux (Jena s99) inversion, which includes more atmospheric measurement sites as the $\mathrm{CO}_{2}$ flux constraint than Jena s81, shows a consistent result and strength our previous findings. The 16-yr (1999-2014) Jena s99 NCE $\sigma_{\mathrm{NCE} / \mathrm{Tsa}}$ is comparable to the one estimated from 1998 to 2014 in the s81 (Figs. 6a,b). The s99 estimated spring $\sigma_{\mathrm{NCE} / \mathrm{Tsa}}$ in the recent time period is positive, but not significantly different from zero. Summer $\sigma_{\mathrm{NCE} / \mathrm{Tsa}}$ estimated from Jena s99 is even more negative than that of s81. This can also be seen by comparing the spatial patterns of $\sigma_{\mathrm{NCE} / \mathrm{Tsa}}$ derived from Jena s81 (Fig. 7) and s99 (Fig. 8). The decrease in temperature sensitivity of net carbon uptake is also consistent with another independent inversion model CarbonTracker 2016, which shows a temperature 

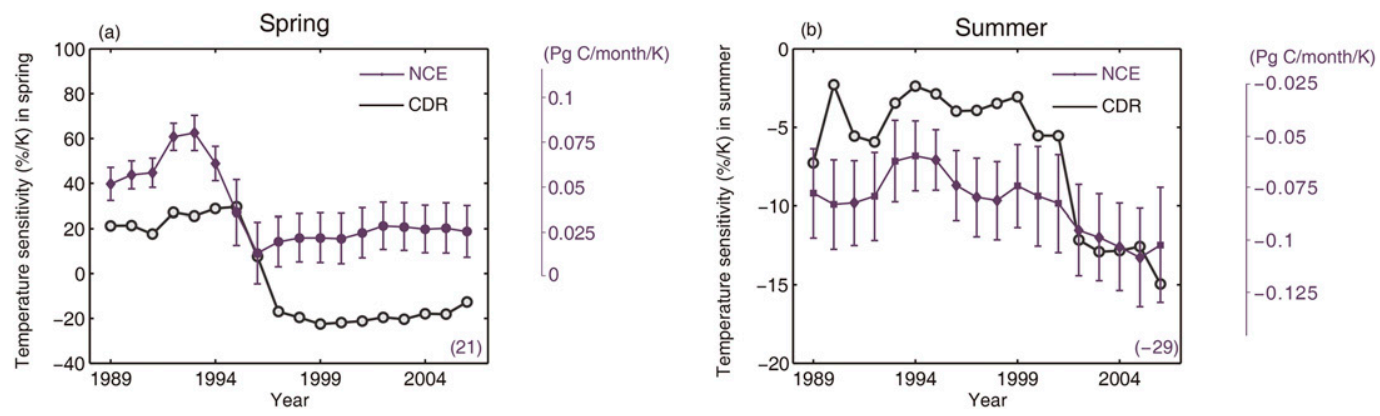

FIG. 6. Temperature sensitivity of (a) spring (May) and (b) summer $\sigma_{\mathrm{NCE} / \mathrm{Tsa}}$ (July-August) using Jena inversion s81 carbon exchange in the 17-yr windows during 1981-2014. When $\sigma_{\mathrm{NCE} / \mathrm{Tsa}}$ is positive, it means warming will stimulate carbon uptake; otherwise, warming causes less carbon uptake. The right axis shows the temperature sensitivity of NCE without standardization with the unit of $\mathrm{PgC}$ month ${ }^{-1} \mathrm{~K}^{-1}$. Black lines in (a) and (b) show the corresponding temperature sensitivity of CDR. Symbols in the line means the same as symbols in Fig. 3. Error bars indicate the standard errors derived from 17-yr moving windows with bootstrap estimates. Another version of Jena inversion (s99) is also used to show the temperature sensitivity of NCE in the last 16 years (1999-2014), which is shown as the numbers in parentheses in (a) and (b) corresponding to year of 2006.

sensitivity of $-9 \%$ and $-21 \%{ }^{\circ} \mathrm{C}^{-1}$ during the period of 1999-2014 for spring and summer, respectively.

Analysis of two GPP products showed that the temperature sensitivity of GPP decreased during summer but remained stable during spring. The temperature sensitivity of detrended GPP ( $\left.\sigma_{\mathrm{GPP} / \mathrm{Tsa}}\right)$ in both products show a decreasing trend in summer, but no significant trend in spring (Figs. 9c,d). The temporal pattern of summer $\left(\sigma_{\mathrm{GPP} / \mathrm{Tsa}}\right)$ is similar to $\sigma_{\mathrm{CDR} / \mathrm{Tsa}}$. Both metrics stay relatively stable before 1999 and after that both show a steep reduction (cf. Figs. 3 b and 9d), suggesting that the decrease in $\sigma_{\mathrm{GPP} / \mathrm{Tsa}}$ is the main driver of the more negative summer $\sigma_{\mathrm{CDR} / \mathrm{Tsa}}$ over time. When the whole NHL is divided into NA and EA, spring $\left(\sigma_{\mathrm{GPP} / \mathrm{Tsa}}\right)$ in EA and NA shows an insignificant trend in both products (Fig. S6). However, both NA and EA show a decreasing summer $\left(\sigma_{\mathrm{GPP} / \mathrm{Ts}}\right)$ in both GPP products (Fig. S6). This declining temperature sensitivity of photosynthesis in summer might be caused by 1) a nonlinear response of photosynthesis to warming (Fig. S7). The temperature response curve of photosynthesis is parabolic and peaks at some optimal temperature (Gent and Seginer 2012), which is normally higher than the mean temperature across NHL, and/or 2) pervasive warming increases the number of extreme hot days (Piao et al. 2014), which could adversely affect GPP through forest cover loss (Anderegg et al. 2013).

Weakened spring $\sigma_{\mathrm{CDR} / \mathrm{Tsa}}$ does not appear to be driven by changing GPP due to the lack of significant decreasing trend in $\left(\sigma_{\mathrm{GPP} / \mathrm{Tsa}}\right)$. So we used smaller running windows $(11 \mathrm{yr})$ to get more detailed transitional information on the weakened Tsa-CDR correlation in spring and found a breakpoint in the time series of partial correlation between Tsa and CDR (Fig. 10a).
The breakpoint, as determined by a piecewise linear model, was identified in 1992, corresponding to the running window of 1987-97, after which the response shows a steep reduction in the partial correlation between CDR and Tsa. When we used running time windows of 13 and 15 years, the breakpoint is located in 1992 and 1990, which corresponds to the running window of 1986-98 and 1983-97, respectively (Fig. S8). These breakpoint analyses suggest there is an abrupt change when the data after the year 1997 is included. The temporally correspondent change in FDD, which characterizes the soil thaw or freeze status (Frauenfeld et al. 2007), seems to explain the change in temperature sensitivity of net carbon uptake. We find there is also a breakpoint in 1997: FDD decreased until 1997 and after that it becomes flat (Fig. 10b). The slowdown in FDD changing rate after 1997 indicates the slowdown of the soil thaw rate, which potentially influences the soil hydrological status and nutrient availability (Sjursen et al. 2005) and thus the soil respiration (Mikan et al. 2002). The possible reason might be due to the lagged soil response to temperature (Oikawa et al. 2014), as the FDD after 1997 is nevertheless getting lower. The soil carbon decomposition takes some time to adjust to a new status. In addition, we also find the phase transition of mean January-May AMO from negative to positive just occurred around year 1997 (Fig. 10c), which suggests this weakened relation between Tsa and CDR and the associated soil thermal or freeze change might be modulated by the multidecadal internal climate variability (Mann et al. 2014; Steinman et al. 2015).

The decrease in temperature sensitivity of net carbon uptake seems to be enhanced in warmer climate. To better understand the impact of ongoing warming on the 


\section{Spring}

(a)

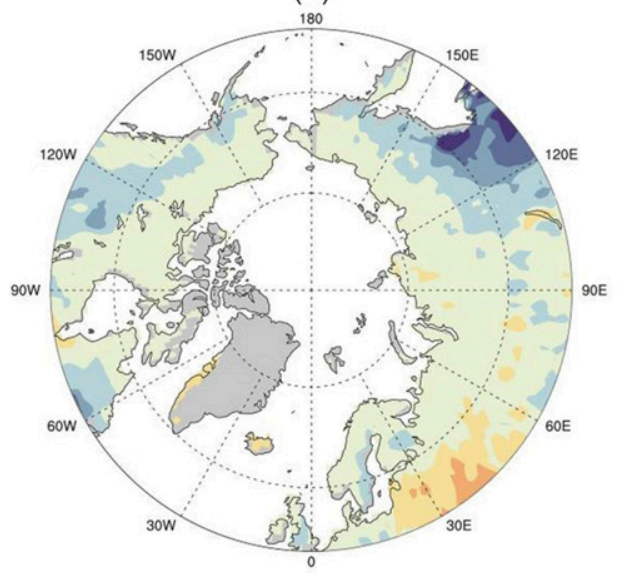

(c)

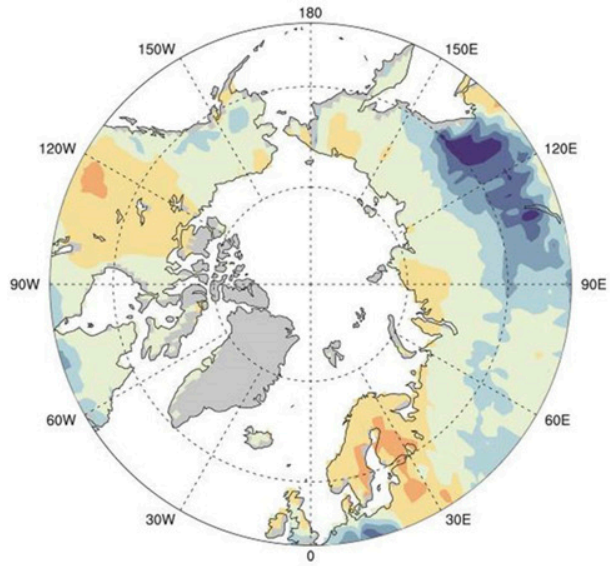

(e)

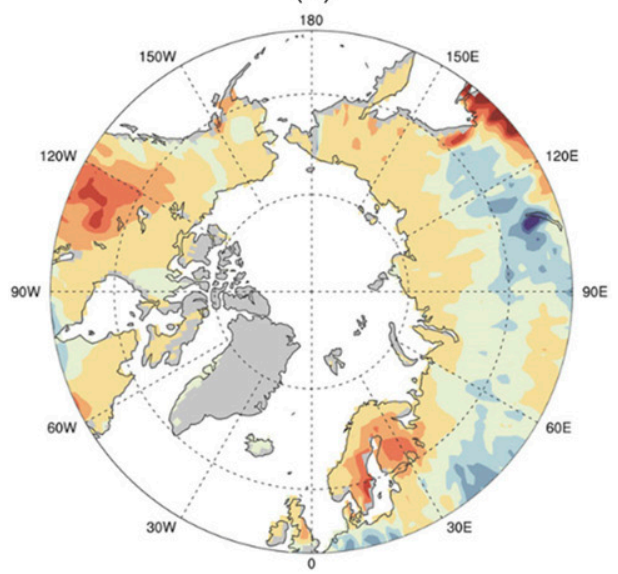

Summer

(b)

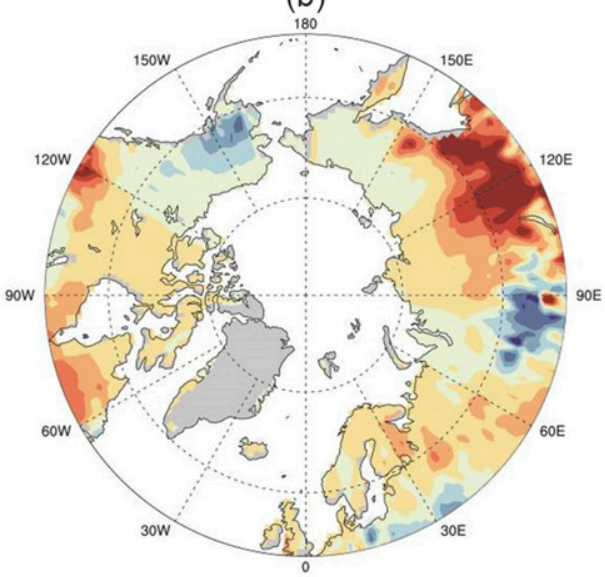

(d)

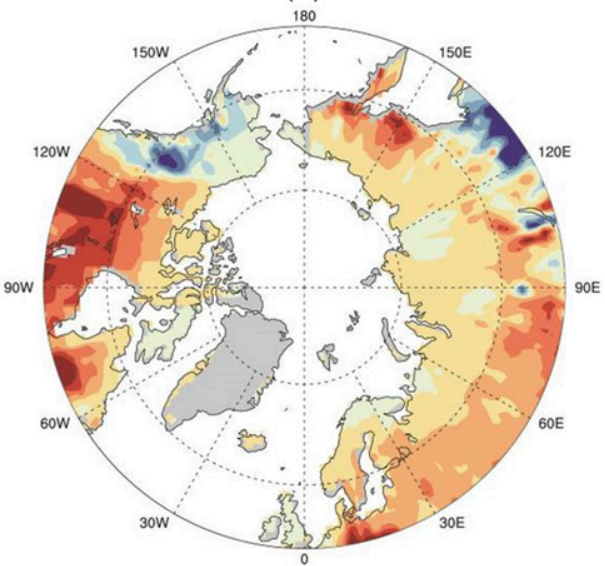

(f)

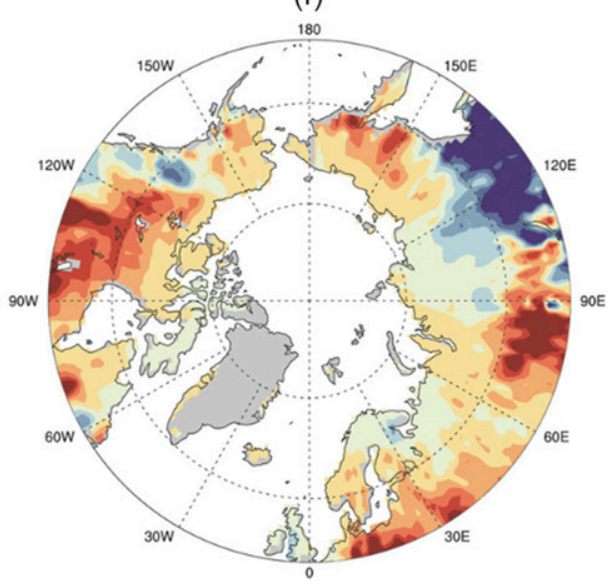

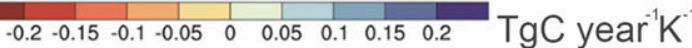

FIG. 7. The spatial pattern of temperature sensitivity of (a),(c) spring and (b),(d) summer NCE from s81_v3.7 Jena inversion carbon flux $\left(\sigma_{\mathrm{NCE} / \mathrm{Tsa}} ; \mathrm{Tg} \mathrm{C} \mathrm{yr}^{-1} \mathrm{~K}^{-1}\right)$ for the $(\mathrm{a})$, (b) first 17 years $(1981-97)$ and (c),(d) last 17 years (1998-2014) during 1981-2014 over the area north of 50 $\mathrm{N}$. Also shown are the changes in $d \mathrm{NCE} / d$ Tsa in (e) spring and (f) summer between the first 17 and last 17 years during 19822011. 


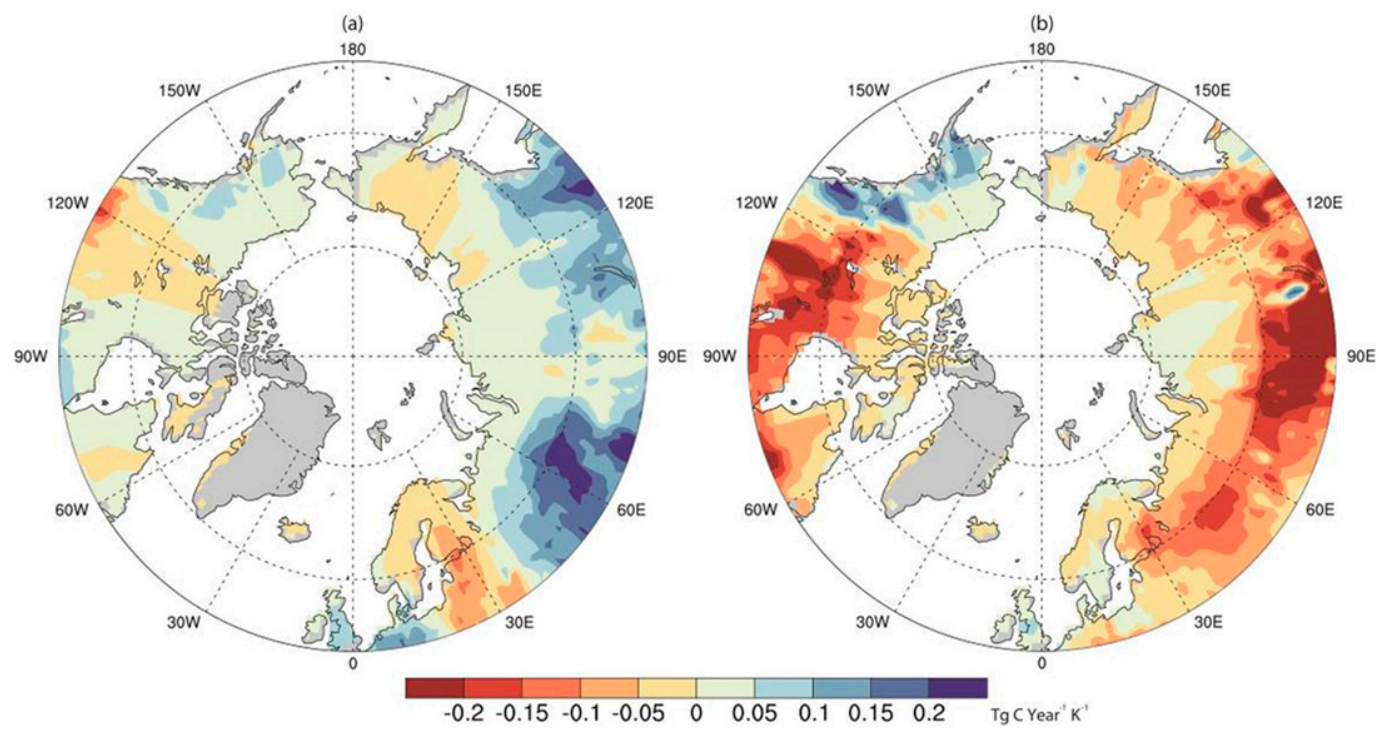

FIG. 8. The spatial pattern of temperature sensitivity of (a) spring and (b) summer NCE from s99 Jena inversion carbon exchange $\left(\sigma_{\mathrm{NCE} / \mathrm{Tsa}} ; \mathrm{Tg} \mathrm{Cyr}^{-1} \mathrm{~K}^{-1}\right)$ for the latest 16 years $(1999-2014)$ over the area north of $50^{\circ} \mathrm{N}$.

decreasing temperature sensitivity of net carbon uptake, all the years in the time series of CDR, GPP, and NCE from Jena inversions were divided into warmer and cooler groups based on the median value of temperature time series. The warmer years consistently have a lower temperature sensitivity of CDR, GPP, and NCE in both spring and summer (Fig. 11). Generally, the differences of temperature sensitivity of CDR and NCE in summer between warmer/cooler groups of years are more significant than those in spring. The lower temperature sensitivity of summer GPP in warmer years (Fig. 11) suggests that warming could potentially contribute to the more negative summer $\sigma_{\mathrm{CDR} / \mathrm{Tsa}}$, although in the long term other factors like $\mathrm{CO}_{2}$ fertilization may interact with temperature effects.

TRENDY model estimated $\sigma_{\mathrm{NCE} / \mathrm{Ts} a}$ values do not show the decrease in $\sigma_{\mathrm{NCE} / \mathrm{Ts}}$ as suggested by the observational data. GPP and NCE from the TRENDY model project (v1) over 1974-2010 are used to determine if global carbon models produce outputs consistent with this study. When estimating temperature sensitivity of NCE and GPP, climate forcing data from TRENDY model project were used. The multimodel mean of the first 17 and last 17 years of GPP-temperature sensitivity was consistent with the patterns we found for satellite GPP products (Figs. 12a,b). However, for NCE, no single model or model ensemble mean could reproduce the weakened temperature sensitivity in spring and the reversal of temperature sensitivity from positive to negative in summer shown by the inversion NCE and observed CDR (Figs. 12c,d), highlighting the potential role of ecosystem respiration, another component of NCE that needs to be better represented in current models. We also showed the temporal evolution
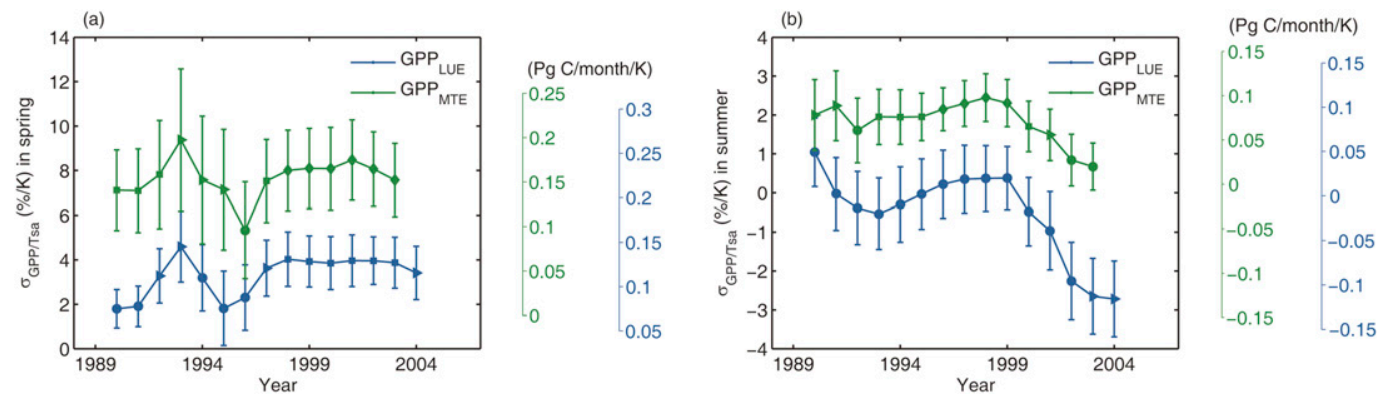

FIG. 9. The temperature sensitivity of (a) spring (May) and (b) summer (July-August) $\sigma_{\mathrm{GPP} / \mathrm{Tsa}}$ in the 17-yr windows for GPP MTE $_{\text {and GPP }}$ LUE over NHL. GPP and climate variables are area weighted over vegetated area. The right axis shows the temperature sensitivity of GPP without standardization with the unit of $\mathrm{PgC} \mathrm{month}{ }^{-1} \mathrm{~K}^{-1}$. Symbols in the line mean the same as symbols in Fig. 3. Error bars indicate the standard errors derived from 17-yr moving windows with bootstrap estimates. 
(a)

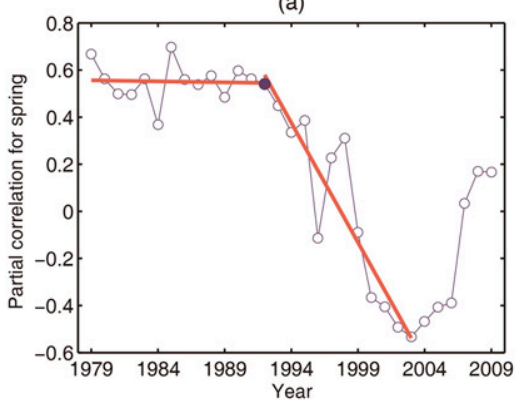

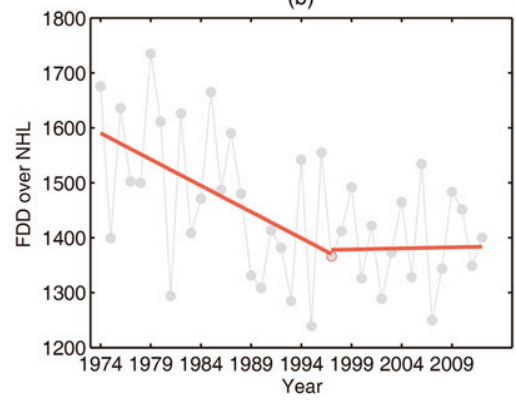

(c)

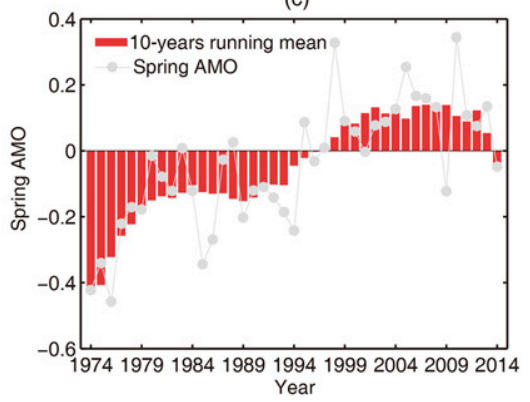

FIG. 10. Breakpoints in the time series of partial correlation between spring temperature and CDR and northern high-latitude freezing degree-days, AMO. The Atlantic multidecadal oscillation (AMO) is a teleconnection index obtained by detrending North Atlantic sea surface temperature anomalies. (a) The time series of partial correlation between spring temperature and CDR. The marked point represents the breakpoint year 1992, which is the first year in the time series of partial correlation including the data of 1997 in the 11-yr running windows. The breakpoint is determined by piecewise linear model and the red solid line represents the two linear regression models. (b) The time series of northern high-latitude freezing degree-days (FDD) over January-May. (c) The time series of mean monthly AMO over January-May and its 10-yr running mean.

of $\sigma_{\mathrm{GPP} / \mathrm{Tsa}}$ and $\sigma_{\mathrm{NCE} / \mathrm{Tsa}}$ over NA and EA separately in Figs. S9-S12, which suggests that the increase in $\sigma_{\mathrm{GPP} / \mathrm{Tsa}}$ and $\sigma_{\mathrm{NCE} / \mathrm{Tsa}}$ for the whole NHL is mainly driven by the corresponding increase in NA. The uncertainty introduced by climate forcing data bias on the estimation of carbon flux with processed-based ecosystem models was not considered in this analysis. It would be helpful if this uncertainty is considered in future multimodel intercomparison projects to increase the confidence in the associated future projections of carbon flux (Ahlström et al. 2017).

\section{Discussion and concluding remarks}

Our study documented a downward sensitivity of the carbon uptake to interannual temperature in the NHL region over recent decades. The results extend recent findings by Piao et al. (2017) in spring to summer trends as well. These results are also consistent with studies using tree-ring analysis and techniques to assess the temperature sensitivity of vegetation growth (Piao et al. 2014; D'Arrigo et al. 2008; Wilmking et al. 2005). The analysis of inversion results support the CDR findings based on $\mathrm{CO}_{2}$ surface measurements from Barrow, Alaska. This confirmation is important because of the potential bias of trends at Barrow due to the contribution of $\mathrm{CO}_{2}$ flux transported from the nearby ocean surface and anthropogenic sources. In future studies, further analysis employing ocean general circulation models could investigate the contribution of airsea $\mathrm{CO}_{2}$ exchange to the decreasing temperature sensitivity.
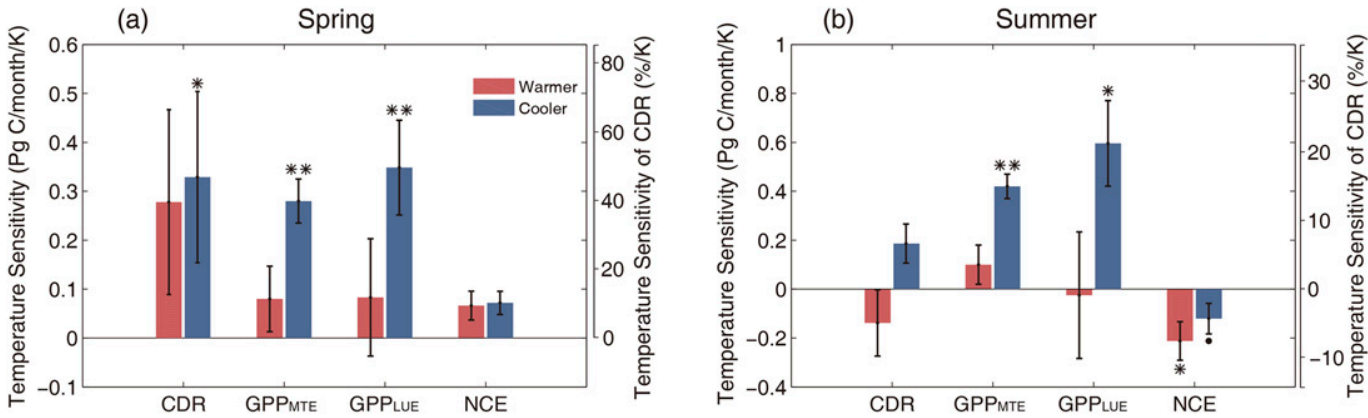

FIG. 11. Temperature sensitivity of CDR, GPP, and NCE in warmer/cooler years. Temperature sensitivity of CDR, GPP, and NCE in (a) spring and (b) summer is calculated by regressing detrended CDR, GPP, and NCE over detrended Tsa and Prec. The term $\sigma_{\mathrm{CDR} / \mathrm{Tsa}}$ is obtained by standardization using the mean CDR to get the percentage change per K. Each time series of CDR, GPP, and NCE is divided into two groups, warmer and cooler based on the corresponding temperature: the years with higher temperature than the median are defined as warmer years, and the others as cooler years. The error bar shows the stand error of temperature sensitivity, derived from each group with 5000 bootstrap estimates. A dot $(\cdot)$ indicates the significance at $p<0.1$ level, an asterisk (*) indicates the significance at $p<0.05$ level, and two asterisks (**) indicate significance at $p<0.01$ level. 
(a)
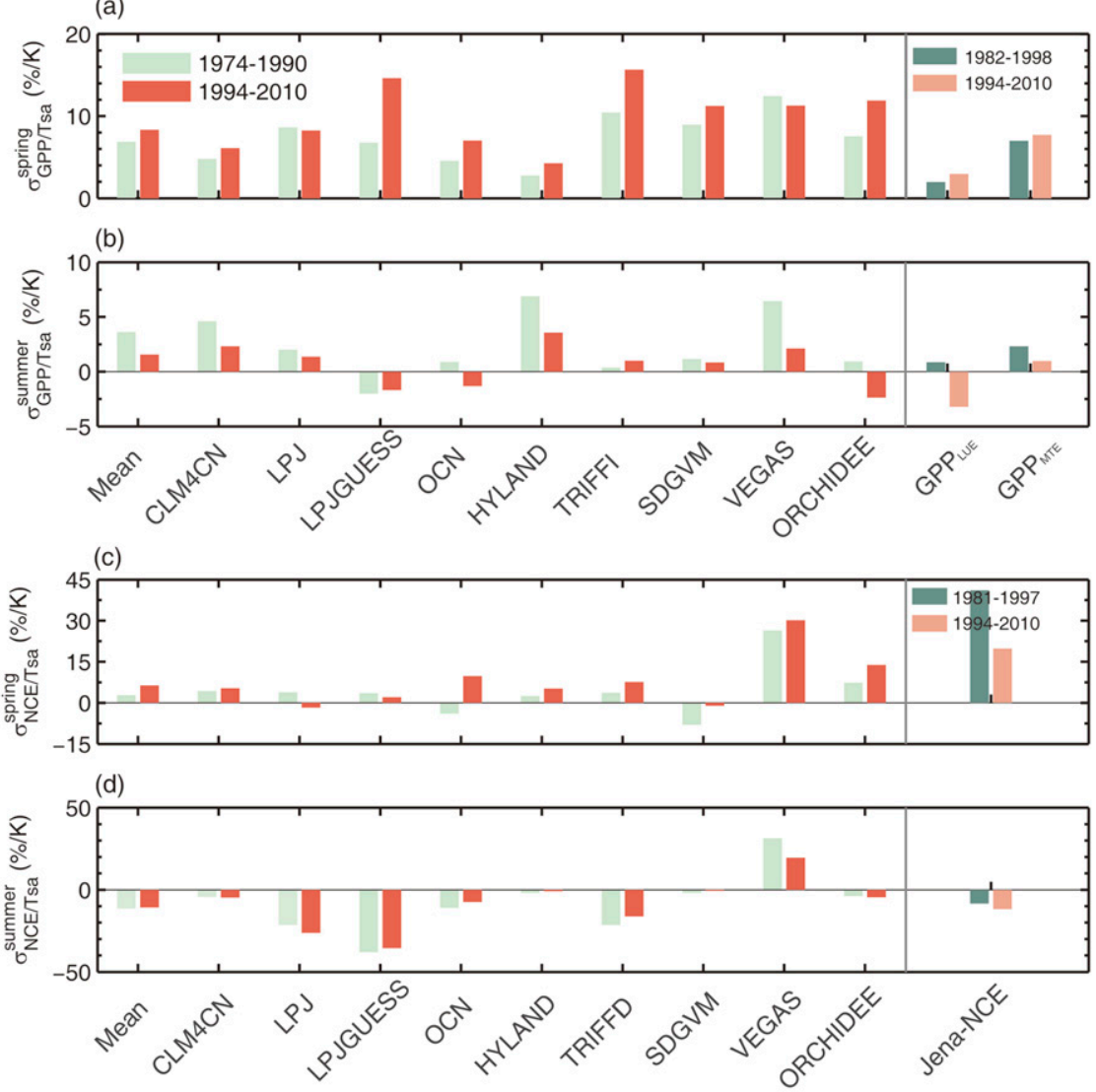

FIG. 12. Temperature sensitivity of GPP and NCE in TRENDY models over 1974-2010. The temperature sensitivity of (a) spring and (b) summer $\sigma_{\mathrm{GPP} / \mathrm{Tsa}}$ for the first 17-yr (1974-90) and last 17-yr (1994-2010) windows during 1974-2011 over northern high latitudes for 9 models in TRENDY. The temperature sensitivity of (c) spring and (d) summer $\sigma_{\mathrm{NCE} / \mathrm{Tsa}}$ for the first $17-\mathrm{yr}$ (1974-90) and last 17-yr (1994-2010) windows during 1974-2011 over northern high latitudes for nine models in TRENDY. The temporal evolution of $\sigma_{\mathrm{GPP} / \mathrm{Ts} a}$ and $\sigma_{\mathrm{GPP} / \mathrm{Tsa}}$ are shown in Figs. S9-S12. Here we also show the mean of nine modeled GPP, NCE, and observational data based GPP and inversion NCE as a comparison.

Piao et al. (2017) attributed spring sensitivity decline to the declining net primary productivity sensitivity. Our analysis of satellite-derived GPP showed no change in temperature sensitivity of GPP, so we conclude that changes in GPP are unlikely drivers to the observed sensitivity changes. Instead, a warming-induced higher rate of soil respiration than GPP confirmed by BondLamberty et al. (2018) might be responsible for the weakening sensitivity of CDR in spring.

The multiple lines of evidence presented here suggest a weakened positive and even negative effect of warming on the interannual variability of the NHL growing season carbon uptake and also shed light on which processes might be responsible for it. Our analysis of freezing degree days provides a plausible explanation for the spring sensitivity decline: the coincident change in soil frozen status, implying the consequent change in soil hydrological or nutrient status might be responsible. In terms of the intensified negative interannual temperature sensitivity in summer, our analysis indicated it is connected with the warming caused decrease in temperature sensitivity of photosynthesis.

Together with previously addressed Northern Hemisphere warming-induced carbon loss in autumn (Piao et al. 2008), it is likely that future warming in the NHL will continue to drive decreased temperature sensitivity and might eventually weaken the net carbon uptake. The underlying mechanism of decreasing temperature sensitivity of net carbon uptake is still unresolved due to the complex responses of carbon fluxes to environmental change. Extreme events such as droughts, heat waves, and frosts might severely decrease plant productivity and its recovery to the normal carbon-storage capacity might be significantly delayed (Frank et al. 
2015); however, these influences were not well characterized in current land ecosystem models. In terms of the belowground processes, warming-induced permafrost thawing, the interactive effect among $\mathrm{CO}_{2}$ enrichment, warming, and soil nutrients (Luo et al. 2016; Dieleman et al. 2012), and the change in microbial communities (Xue et al. 2016) are critical to regulating soil carbon decomposition. Our analysis also implied that belowground processes could be the primary driving factor of temperature sensitivity decrease in spring; however, they are currently difficult to represent with sufficient certainty.

The TRENDY ecosystem models failed to represent the change in temperature sensitivity of net carbon fluxes and implied belowground processes might be responsible for such discrepancy. Therefore, more efforts are required to improve our understanding of the different responses of spring and summer carbon uptake to interannual temperature variability and cascading effects of warming on belowground processes, like permafrost thaw or freeze and changes in soil microbial communities (Xue et al. 2016). We highlight the need for field experiments to inform process-based models to improve the simulation of carbon exchange between the atmosphere and terrestrial ecosystems across NHL.

This study examined how temperature sensitivity of NHL net carbon uptake changes by integrating atmospheric $\mathrm{CO}_{2}$ record, atmospheric inversion model, and process-based ecosystem model. These lines of evidence supported the main conclusion by a previous study (Piao et al. 2017) and provided a novel framework to connect the weakening spring sensitivity with the change in soil frozen processes. Considering the changes in soil moisture and microbial community due to soil freeze-thaw dynamics may help explain the increase in soil respiration is faster than GPP with warming in recent decades to better understand these carbon sink and source contributions to the regional carbon budget (Bond-Lamberty et al. 2018).

Acknowledgments. This research was supported by an NSF project (IIS-1027955) and a NASA LCLUC project grant (NNX09AI26G) to Q. Z. We acknowledge the Rosen High Performance Computing Center at Purdue for computing support. TFK was supported by the Director, Office of Science, Office of Biological and Environmental Research of the U.S. Department of Energy under Contract DE-AC02-05CH11231 as part of the RuBiSCo SFA. We thank comments from David Kicklighter and Dave McGuire. We also thank TRENDY team for providing the DGVM simulations and the researchers of NOAA/Earth System Research
Laboratory for making their $\mathrm{CO}_{2}$ observation data available. Any use of trade, firm, or product names is for descriptive purposes only and does not imply endorsement by the U.S. government. The authors declare no competing financial interests.

\section{REFERENCES}

Ahlström, A., G. Schurgers, and B.Smith, 2017. The large influence of climate model bias on terrestrial carbon cycle simulations. Environ. Res. Lett., 12, 014004, https://doi.org/10.1088/17489326/12/1/014004.

Albergel, C., and Coauthors, 2015: Soil temperature at ECMWF: An assessment using ground-based observations. J. Geophys. Res., 120, 1361-1373, https://doi.org/10.1002/2014JD022505.

Anderegg, W. R. L., J. M. Kane, and L. D. L. Anderegg, 2013: Consequences of widespread tree mortality triggered by drought and temperature stress. Nat. Climate Change, 3, 3036, https://doi.org/10.1038/nclimate1635.

Angert, A., S. Biraud, C. Bonfils, C. C. Henning, W. Buermann, J. Pinzon, C. J. Tucker, and I. Fung, 2005: Drier summers cancel out the $\mathrm{CO}_{2}$ uptake enhancement induced by warmer springs. Proc. Natl. Acad. Sci. USA, 102, 10 823-10 827, https:// doi.org/10.1073/pnas.0501647102.

Balsamo, G. P., A. Beljaars, K. Scipal, P. Viterbo, B. van den Hurk, M. Hirschi, and A. K. Betts, 2009: A revised hydrology for the ECMWF model: Verification from field site to terrestrial water storage and impact in the Integrated Forecast System. J. Hydrometeor., 10, 623-643, https://doi.org/10.1175/ 2008JHM1068.1.

Barber, V. A., G. P. Juday, and B. P. Finney, 2000: Reduced growth of Alaskan white spruce in the twentieth century from temperature-induced drought stress. Nature, 405, 668-673, https://doi.org/10.1038/35015049.

Barnes, M. L., and Coauthors, 2016: Vegetation productivity responds to sub-annual climate conditions across semiarid biomes. Ecosphere, 7, e01339, https://doi.org/10.1002/ecs2.1339.

Belshe, E. F., E. A. G. Schuur, and B. M. Bolker, 2013: Tundra ecosystems observed to be $\mathrm{CO}_{2}$ sources due to differential amplification of the carbon cycle. Ecol. Lett., 16, 1307-1315, https://doi.org/10.1111/ele.12164.

Bond-Lamberty, B., V. L. Bailey, M. Chen, C. M. Gough, and R. Vargas, 2018: Globally rising soil heterotrophic respiration over recent decades. Nature, 560, 80-83, https://doi.org/ 10.1038/s41586-018-0358-x.

Burke, E. J., R. Dankers, C. D. Jones, and A. J. Wiltshire, 2013: A retrospective analysis of pan Arctic permafrost using the JULES land surface model. Climate Dyn., 41, 1025-1038, https://doi.org/10.1007/s00382-012-1648-x.

Cai, T., L. B. Flanagan, and K. H. Syed, 2010: Warmer and drier conditions stimulate respiration more than photosynthesis in a boreal peatland ecosystem: Analysis of automatic chambers and eddy covariance measurements. Plant Cell Environ., 33, 394-407, https://doi.org/10.1111/j.1365-3040.2009.02089.x.

Commane, R., and Coauthors, 2017: Carbon dioxide sources from Alaska driven by increasing early winter respiration from Arctic tundra. Proc. Natl. Acad. Sci. USA, 114, 5361-5366, https://doi.org/10.1073/pnas.1618567114.

D'Arrigo, R., R. Wilson, B. Liepert, and P. Cherubini, 2008: On the "divergence problem" in northern forests: A review of the tree-ring evidence and possible causes. Global Planet. Change, 60, 289-305, https://doi.org/10.1016/j.gloplacha.2007.03.004. 
Dieleman, W. I. J., and Coauthors, 2012: Simple additive effects are rare: A quantitative review of plant biomass and soil process responses to combined manipulations of $\mathrm{CO}_{2}$ and temperature. Global Change Biol., 18, 2681-2693, https://doi.org/ 10.1111/j.1365-2486.2012.02745.x.

Forbes, B. C., M. M. Fauria, and P. Zetterberg, 2010: Russian Arctic warming and "greening" are closely tracked by tundra shrub willows. Global Change Biol., 16, 1542-1554, https:// doi.org/10.1111/j.1365-2486.2009.02047.x.

Frank, D., and Coauthors, 2015: Effects of climate extremes on the terrestrial carbon cycle: Concepts, processes and potential future impacts. Global Change Biol., 21, 2861-2880, https:// doi.org/10.1111/gcb.12916.

Frauenfeld, O. W., T. Zhang, and J. L. McCreight, 2007: Northern Hemisphere freezing/thawing index variations over the twentieth century. Int. J. Climatol., 27, 47-63, https://doi.org/ 10.1002/joc. 1372 .

Gent, M. P. N., and I. Seginer, 2012: A carbohydrate supply and demand model of vegetative growth: Response to temperature and light. Plant Cell Environ., 35, 1274-1286, https://doi.org/ 10.1111/j.1365-3040.2012.02488.x.

Goetz, S. J., and Coauthors, 2005: Satellite-observed photosynthetic trends across boreal North America associated with climate and fire disturbance. Proc. Natl. Acad. Sci. USA, 102, 13 521-13 525, https://doi.org/10.1073/pnas.0506179102.

Graven, H. D., and Coauthors, 2013: Enhanced seasonal exchange of $\mathrm{CO}_{2}$ by northern ecosystems since 1960 . Science, 341, 10851089, https://doi.org/10.1126/science.1239207.

Hayes, D. J., A. D. McGuire, D. W. Kicklighter, K. R. Gurney, T. J. Burnside, and J. M. Melillo, 2011: Is the northern high-latitude land-based $\mathrm{CO}_{2}$ sink weakening? Global Biogeochem. Cycles, 25, GB3018, https://doi.org/10.1029/2010GB003813.

Huffman, G. J., R. F. Adler, M. M. Morrissey, D. T. Bolvin, S. Curtis, R. Joyce, B. McGavock, and J. Susskind, 2001: Global precipitation at one-degree daily resolution from multisatellite observations. J. Hydrometeor., 2, 36-50, https://doi.org/10.1175/ 1525-7541(2001)002<0036:GPAODD > 2.0.CO;2.

, and Coauthors, 2007: The TRMM Multisatellite Precipitation Analysis (TMPA): Quasi-global, multiyear, combinedsensor precipitation estimates at fine scales. J. Hydrometeor., 8, 38-55, https://doi.org/10.1175/JHM560.1.

Jeong, S. J., and Coauthors, 2018: Accelerating rates of Arctic carbon cycling revealed by long-term atmospheric $\mathrm{CO}_{2}$ measurements. Sci. Adv., 4, eaao1167, https://doi.org/10.1126/ sciadv.aao1167.

Jung, M., and Coauthors, 2011: Global patterns of landatmosphere fluxes of carbon dioxide, latent heat, and sensible heat derived from eddy covariance, satellite, and meteorological observations. J. Geophys. Res. Biogeosci., 116, G00J07, https://doi.org/10.1029/2010JG001566.

Kalnay, E., and Coauthors, 1996: The NCEP/NCAR 40-Year Reanalysis Project. Bull. Amer. Meteor. Soc., 77, 437-471, https:// doi.org/10.1175/1520-0477(1996)077<0437:TNYRP>2.0.CO;2.

Keenan, T. F., I. C. Prentice, J. G. Canadell, C. A. Williams, H. Wang, M. Raupach, and G. J. Collatz, 2016: Recent pause in the growth rate of atmospheric $\mathrm{CO}_{2}$ due to enhanced terrestrial carbon uptake. Nat. Commun., 7, 13428, https:// doi.org/10.1038/ncomms13428; Corrigendum, 7, 16137, https:// doi.org/10.1038/ncomms16137.

Keuper, F., and Coauthors, 2012: A frozen feast: Thawing permafrost increases plant-available nitrogen in subarctic peatlands. Global Change Biol., 18, 1998-2007, https://doi.org/10.1111/ j.1365-2486.2012.02663.x.
Koven, C. D., and Coauthors, 2011: Permafrost carbon-climate feedbacks accelerate global warming. Proc. Natl. Acad. Sci. USA, 108, 14 769-14 774, https://doi.org/10.1073/pnas. 1103910108.

Kurz, W. A., C. C. Dymond, G. Stinson, G. J. Rampley, E. T. Neilson, A. L. Carroll, T. Ebata, and L. Safranyik, 2008: Mountain pine beetle and forest carbon feedback to climate change. Nature, 452, 987-990, https://doi.org/10.1038/nature06777.

Lawrence, D. M., C. D. Koven, S. C. Swenson, W. J. Riley, and A. G. Slater, 2015: Permafrost thaw and resulting soil moisture changes regulate projected high-latitude $\mathrm{CO}_{2}$ and $\mathrm{CH}_{4}$ emissions. Environ. Res. Lett., 10, 094011, https://doi.org/10.1088/ 1748-9326/10/9/094011.

Liu, Y., and Coauthors, 2015: Evapotranspiration in northern Eurasia: Impact of forcing uncertainties on terrestrial ecosystem model estimates. J. Geophys. Res. Atmos., 120, $2647-$ 2660, https://doi.org/10.1002/2014JD022531.

Lloyd, J., and G. D. Farquhar, 1996: The $\mathrm{CO}_{2}$ dependence of photosynthesis, plant growth responses to elevated atmospheric $\mathrm{CO}_{2}$ concentrations and their interaction with soil nutrient status. I. General principles and forest ecosystems. Funct. Ecol., 10, 4-32, https://doi.org/10.2307/2390258.

Luo, Y., and Coauthors, 2016: Toward more realistic projections of soil carbon dynamics by Earth system models. Global Biogeochem. Cycles, 30, 40-56, https://doi.org/10. 1002/2015GB005239.

Macias-Fauria, M., B. C. Forbes, P. Zetterberg, and T. Kumpula, 2012: Eurasian Arctic greening reveals teleconnections and the potential for structurally novel ecosystems. Nat. Climate Change, 2, 613-618, https://doi.org/10.1038/nclimate1558.

Mann, M. E., B. A. Steinman, and S. K. Miller, 2014: On forced temperature changes, internal variability, and the AMO. Geophys. Res. Lett., 41, 3211-3219, https://doi.org/10.1002/ 2014GL059233.

McGuire, A. D., and Coauthors, 2009: Sensitivity of the carbon cycle in the Arctic to climate change. Ecol. Monogr., 79, 523555, https://doi.org/10.1890/08-2025.1.

Mikan, C. J., J. P. Schimel, and A. P. Doyle, 2002: Temperature controls of microbial respiration in Aarctic tundra soils above and below freezing. Soil Biol. Biochem., 34,1785-1795, https:// doi.org/10.1016/S0038-0717(02)00168-2.

Mitchell, T. D., and P. D. Jones, 2005: An improved method of constructing a database of monthly climate observations and associated high-resolution grids. Int. J. Climatol., 25, 693-712, https://doi.org/10.1002/joc.1181.

Nemani, R. R., C. D. Keeling, H. Hashimoto, W. M. Jolly, S. C. Piper, C. J. Tucker, R. B. Myneni, and S. W. Running, 2003: Climate-driven increases in global terrestrial net primary production from 1982 to 1999. Science, 300, 1560-1563, https:// doi.org/10.1126/science.1082750.

Oikawa, P. Y., D. A. Grantz, A. Chatterjee, J. E. Eberwein, L. A. Allsman, and G. D. Jenerette, 2014: Unifying soil respiration pulses, inhibition, and temperature hysteresis through dynamics of labile soil carbon and $\mathrm{O}_{2}$. J. Geophys. Res. Biogeosci., 119, 521-536, https://doi.org/10.1002/2013JG002434.

Parazoo, N. C., and Coauthors, 2016: Detecting regional patterns of changing $\mathrm{CO}_{2}$ flux in Alaska. Proc. Natl. Acad. Sci. USA, 113 7733-7738, https://doi.org/10.1073/pnas.1601085113.

Pastick, N. J., M. T. Jorgenson, B. K. Wylie, S. J. Nield, K. D. Johnson, and A. O. Finley, 2015: Distribution of near-surface permafrost in Alaska: Estimates of present and future conditions. Remote Sens. Environ., 168, 301-315, https://doi.org/ 10.1016/j.rse.2015.07.019. 
Peng, C., and Coauthors, 2011: A drought-induced pervasive increase in tree mortality across Canada's boreal forests. Nat. Climate Change, 1, 467-471, https://doi.org/10.1038/ nclimate1293.

Peters, W., and Coauthors, 2010: Seven years of recent European net terrestrial carbon dioxide exchange constrained by atmospheric observations. Global Change Biol., 16, 1317-1337, https://doi.org/10.1111/j.1365-2486.2009.02078.x.

Piao, S., and Coauthors, 2008: Net carbon dioxide losses of northern ecosystems in response to autumn warming. Nature, 451, 49-52, https://doi.org/10.1038/nature06444.

__ , and Coauthors, 2014: Evidence for a weakening relationship between interannual temperature variability and northern vegetation activity. Nat. Commun., 5, 5018, https://doi.org/ 10.1038/ncomms6018.

- , and Coauthors, 2017: Weakening temperature control on the interannual variations of spring carbon uptake across northern lands. Nat. Climate Change, 7, 359-363, https://doi.org/ 10.1038/nclimate3277.

Rödenbeck, C., 2005: Estimating $\mathrm{CO}_{2}$ sources and sinks from atmospheric mixing ratio measurements using a global inversion of atmospheric transport. Max Planck Institute for Biogeochemistry Tech Rep. 6, 53 pp., https://doi.org/10.4126/98004424379.

Schuur, E. A. G., and Coauthors, 2015: Climate change and the permafrost carbon feedback. Nature, 520, 171-179, https:// doi.org/10.1038/nature14338.

Sheffield, J., G. Goteti, and E. F. Wood, 2006: Development of a 50 -year high-resolution global dataset of meteorological forcings for land surface modeling. J. Climate, 19, 3088-3111, https://doi.org/10.1175/JCLI3790.1.

Sippel, S., and Coauthors, 2017: Contrasting and interacting changes in simulated spring and summer carbon cycle extremes in European ecosystems. Environ. Res. Lett., 12, 075006, https://doi.org/10.1088/1748-9326/aa7398.

Sitch, S., and Coauthors, 2015: Recent trends and drivers of regional sources and sinks of carbon dioxide. Biogeosciences, $\mathbf{1 2}$, 653-679, https://doi.org/10.5194/bg-12-653-2015.

Sjursen, H., A. Michelsen, and M. Holmstrup, 2005: Effects of freeze-thaw cycles on microarthropods and nutrient availability in a sub-Arctic soil. Appl. Soil Ecol., 28, 79-93, https:// doi.org/10.1016/j.apsoil.2004.06.003.
Steinman, B. A., M. E. Mann, and S. K. Miller, 2015: Atlantic and Pacific multidecadal oscillations and Northern Hemisphere temperatures. Science, 347, 988-991, https://doi.org/10.1126/ science.1257856.

Sweeney, C., and Coauthors, 2015: Seasonal climatology of $\mathrm{CO}_{2}$ across North America from aircraft measurements in the NOAA/ESRL Global Greenhouse Gas Reference Network. J. Geophys. Res. Atmos., 120, 5155-5190, https://doi.org/ 10.1002/2014JD022591.

Ueyama, M., H. Iwata, and Y. Harazono, 2014: Autumn warming reduces the $\mathrm{CO}_{2}$ sink of a black spruce forest in interior Alaska based on a nine-year eddy covariance measurement. Global Change Biol., 20, 1161-1173, https://doi.org/10.1111/ gcb.12434.

Verbyla, D., 2008: The greening and browning of Alaska based on 1982-2003 satellite data. Global Ecol. Biogeogr., 17, 547-555, https://doi.org/10.1111/j.1466-8238.2008.00396.x.

_ 2011: Browning boreal forests of western North America. Environ. Res. Lett., 6, 041003, https://doi.org/10.1088/17489326/6/4/041003.

Walker, X., and J. F. Johnstone, 2014: Widespread negative correlations between black spruce growth and temperature across topographic moisture gradients in the boreal forest. Environ. Res. Lett., 9, 064016, https://doi.org/10.1088/1748-9326/9/6/064016.

Welp, L. R., J. T. Randerson, and H. P. Liu, 2007: The sensitivity of carbon fluxes to spring warming and summer drought depends on plant functional type in boreal forest ecosystems. Agric. For. Meteor., 147, 172-185, https://doi.org/10.1016/ j.agrformet.2007.07.010

_ P. K. Patra, C. Rödenbeck, R. Nemani, J. Bi, S. C. Piper, and R. F. Keeling, 2016: Increasing summer net $\mathrm{CO}_{2}$ uptake in high northern ecosystems inferred from atmospheric inversions and comparisons to remote-sensing NDVI. Atmos. Chem. Phys., 16, 9047-9066, https://doi.org/10.5194/acp-16-9047-2016.

Wilmking, M., R. D'Arrigo, G. C. Jacoby, and G. P. Juday, 2005: Increased temperature sensitivity and divergent growth trends in circumpolar boreal forests. Geophys. Res. Lett., 32, L15715, https://doi.org/10.1029/2005GL023331.

Xue, K., and Coauthors, 2016: Tundra soil carbon is vulnerable to rapid microbial decomposition under climate warming. Nat. Climate Change, 6, 595-600, https://doi.org/10.1038/ nclimate2940. 